\title{
Research on the "Internet + Traffic" Development Index under the Requirement of Urban Traffic based on the Multiple Regression Model
}

\author{
Mingwei LI \\ Tourism College of Xinyang Normal University, Xinyang, 464000, P.R. China \\ Email:limingwei_happy@163.com
}

\begin{abstract}
The widespread application of "Internet +" technology has enlightened the problemsolving of the increasingly heavy traffic in China. Thus the "Internet + traffic" has been pushed to the leading edge. The numerous researches in the "Internet + traffic" field mainly focus on the strategies of transformation and upgrading the existing traffic system to a more "internet" way, few have ever concerned about the demands on developing "Internet + traffic" of each cities, which was usually treated as for granted. However, as this paper finds out, different cities, based on their urban traffic development, have different levels of "Internet + traffic" development demand. Therefore, in this paper we discuss the development index and construction demand degree of the "Internet + traffic". In addition, we build the multiple regression model and select data of 36 principal cities in China to make clear the construction level and key development areas of "Internet + traffic" under the requirements of urban traffic. Additionally, the prediction model is provided to evaluate the construction degree of separate cities when developing "Internet + traffic". At last, suggestions would be put forward for a better development of the "Internet + traffic".
\end{abstract}

Keywords: Internet +; Internet + traffic; Urban traffic; Multiple regression model; Demand analysis.

\section{Introduction}

In March 2015, the "Internet +" action plan was put forward by Premier Li Keqiang in a government work report in China [1]. Then it has been brought to the height of national strategic level. And the corresponding action plans are put forward by the government at all levels in China, to promote the deep integration and innovation development of the Internet and traditional industries. Finally, the new momentum of economic development would be created in China. As a pillar industry in the traditionally industry, how to take the opportunity in front of the "Internet + " wave and make deeply fusion with it is becoming one of the priority tasks for the transportation industry.

City index data of the "Internet + traffic" shows that the "Internet + transportation project" especially represented by "wisdom city" has spread rapidly in China since year 2016. In this stage, "Internet + traffic" in first-tier and second-tier provincial city has been developing rapidly, thereby being motivated by the overall development of the second and third-tier cities. We expect that the modes of advantages of government and enterprise complement each other and resource sharing and co-construction will be performed in the future. It not only can help traffic transformation and upgrading of more cities also in favor for the co-optimization of urban traffic operation ability and improvement of the transportation service efficiency. Thus, the original pattern has been formed under the collisions of "Internet +" with traffic and its online resources are open and shared while the offline resources run with high quality and efficiency. However, comparing to the rapid advance of technology, it's very weak. At present, the researches of "Internet + traffic" mainly concentrate on the fusion of development mode and path, the Internet's role on the reform of the traditional transportation and the development trend of "Internet + traffic", etc. As we know, researchers are paying more attention to the development of the city "Internet + traffic". That is to say, most researchers did not take the input and output into account when they study the urban traffic demand of the "'Internet + traffic". Just blindly pursuing to improve the development of the "Internet + traffic" is likely to lead the mismatch between the urban traffic demand and "Internet + traffic" and also causing the waste of resources. 
In addition, national investments in "Internet + traffic" are strengthening continuously with the concept development of intelligent transportation, wisdom travel and wisdom city. Here, academia researches are forced to change from the qualitative analysis to quantitative analysis gradually considering the factors of the input-output ratio and application performance in the "Internet + traffic" project. Therefore, in the "Internet +" age, China got various types of urban transportation development based on the present situation and the residents travel characteristics. Firstly, the current development situation of the urban transportation demand for "Internet + traffic" is put forward. Secondly, quantitative researches are carried out on the demand degree of urban transportation for "Internet + traffic". It is not only conducive to establish reasonable plans for the progress of the "Internet + traffic", but also has some auxiliary function on the optimization of urban traffic and traffic congestion.

At present, there are already some scholars exploring the "Internet + traffic" development and corresponding countermeasures of urban traffic congestion from different angles based on the information platform. On the "Internet + traffic" level, LI Ming-wei (2016) [2] proposed the five main fusion advance modes of "Internet + traffic" through applying the cross-border integration mind. They are the integrated transportation information platform construction supported by the big data and the Internet technical, the improvement of the public transportation by the mobile Internet thought fusion technologies, the Internet platform to promote comprehensive logistics transportation efficiency and service process, the "Internet + intelligent transportation" that can promote the construction of intelligent traffic and intelligent city, and also the service development based on the resource intensive sharing. Then corresponding development modes of "Internet + traffic" are proposed by Luo S., Hao J.H., Xiao Y., Nie X.Y. [3] through exploring based on the big network traffic of "aviation, railway, highway". However, the current key question of the "Internet + traffic" development mode in the municipal traffic was not mentioned. WAGN G.P. [4] selected the "Internet + intelligent transportation" as research object and pointed out the problems and challenges based on mobile Internet resources integration and integrated traffic information service development. ZHAI Jing-tong and WANG Z.P. [5] proposed the universality and the normative development measures of the "Internet + traffic" from the angles of top design, legal system and platform management. ZHAO G.H. [6] put forward the evolutionary process of "Internet + transportation" service, and summed up the policy suggestions for promoting the service development of the "Internet + traffic". Besides, from the research level of information technology to improve the traffic congestion. CHEN G.P. (2016) [7] proposed the mode of using the private car sharing to ease traffic congestion. He put forward three private car sharing platforms based on the perspective of "Internet + traffic". They are the social networking platform, the third-party business platform and government nonprofit platform. Otherwise, some scholars focus on the influence of intelligent transportation system (ITS) application to traffic congestion. Such as, the information technology of GPS, GIS, ETC and car networking in ITS are applied to identify and monitor the city's traffic congestion points, or used to predict traffic jam and congestion management (LU X.Y., 2012 [8]; HU Q.Z., LIU YS., 2012 [9], GUAN S.Q., 2016 [10]). Then the regression model and difference-in-difference model are carried out by LI M.W. [11,12] to evaluate the contribution rate of ITS to urban traffic congestion. And the countermeasures are put forward to prevent traffic congestion and control traffic in the information era.

The researches above studied mainly from the angle of the "Internet + traffic" and the congestion improvement based on ITS technology. While no one has yet studied the coordination degree between the "Internet + traffic" and the present situation of urban transportation development [13]. However, it is necessary to adopt the huge support function of "Internet +" both in urban traffic circulation and transportation's transformation and upgrading into consideration. Such as, the "Internet + traffic" index of Beijing, Guangzhou, Shenzhen, Wuhan, Shanghai are more than $60 \%$, especially in Beijing the index is more than $90 \%$. Then, in order to make them more coordinate between each other, it is necessary to explore the demand degree of contemporary urban traffic development situation to the "Internet + traffic". Therefore, the demand degree of current urban traffic development situation to the "Internet + traffic" is taken into consideration. And the econometric analysis model is made to study the match and coordination degree between them. This paper brings out a different view angle, whose research results play an important role in optimizing the "Internet + traffic" construction the urban traffic problems improvement in the city. Simultaneously, it is crucial to compensate for the gap between the theoretical discussion and practice application in the development process of "Internet + transportation". 


\section{Analysis of the Urban Traffic Development Level}

\subsection{The Affecting Factors of Urban Traffic Development}

With the stepping up of urbanization, the urban traffic problem has become a more and more severe challenge. The cause of all kinds of urban traffic problem can be summed up as the mismatch and uncoordinated between the urban traffic demand and traffic supply [14]. Firstly, in terms of transportation demand, it mainly depends on the urban land and layout, the development of social economy and motor vehicle quantities and other factors. Among them, travel direction, travel distance and travel intensity of predominantly commuter are included in the factors of urban land and layout. However, the total urban transportation demand is determined by the development level of the social economy. And the motorized travel demand is given in the motor vehicles owned [15]. Secondly, traffic supply includes two aspects of dynamic and static traffic supply. Dynamic traffic supply mainly serves for the running vehicles, including road infrastructure constructions of road mileage, road area, road network structure, etc. The static traffic supply mainly serves in the vehicle parking. To alleviate the contradiction between traffic supply and traffic demand, the traffic demand management is widely applied in urban traffic congestion management. But in fact, the problems of urban traffic congestion still cannot be fundamentally solved [16]. Therefore, mentioned influencing factors whose data are quantifiable and the access of the general characteristic of urban traffic smoothness are selected based on the above analysis. Then the factor set is formed and the research of the relationship between urban traffic developments is carried out (Tab.1).

Table 1. The main impact indicators of urban traffic congestion

\begin{tabular}{lll}
\hline Category & Indicator contents & $\begin{array}{c}\text { Relevance to the urban } \\
\text { traffic development }\end{array}$ \\
\hline The social economic & Population GDP & Negative correlation \\
Traffic demand & Motor vehicle ownership Civilian car ownership & Negative correlation \\
& Road mileage, road area & Positive correlation \\
Traffic supply & Public vehicle number & Positive correlation \\
& Public transportation passenger & Positive correlation \\
\hline
\end{tabular}

\section{(1) Population and GDP}

Economic development will bring substantial increase in urban population, and will also lead to a great travel demand. Moreover, economic development could lead to the production of more purchasing power of motor vehicles. Therefore, the more development the urban economy has gained, the greater the traffic travel demand will be, which also means higher requirement of transportation supply and carrying capacity.

(2) Number of motor vehicles

As the visual expression of road traffic and parking demands, vehicle amount largely determines the requirements of motor vehicle travel. In terms of the slowly growing urban roads and tight urban land, the rapid growth of motor vehicles will provide the road with more carrying capacity, which would quickly reach saturation. Besides, the insufficient parking supply capacity will directly result in severe urban traffic congestion.

(3) Road mileage and road area

Urban road is the carrier of urban traffic, and road mileage as well as road areas can directly determine the carrying capacity of the road network. Longer road and larger areas mean more driving smooth of urban traffic. However, due to the restriction of urban planning and land, construction funds and many other factors, the growth rate of urban roads is lower than that of motor vehicle. Taking Beijing as an example, the average annual growth of road mileage was $10.12 \%$ from 2005 to 2010. Excluding the large-scale construction during the 2008 Olympic Games, the average annual growth rate is only 3\%, which is less than $13 \%$ of the average annual growth of motor vehicle.

(4) Number of public vehicle 
After years of exploration, optimizing the traffic travel structure has become more and more important. Besides, improving the carrying capacity and service level of public transport also becomes an important way to solve the urban traffic congestion problem. The number of public vehicle, which plays a positive role in easing urban traffic congestion, could reflect the supply capacity of urban public transport.

(5) Number of public transport passenger

Public transport passenger can describe supply capacity of public transport from the perspective of transportation production. Generally, people believed that with greater amount of public transport passenger, urban transport operation would turn better. At present, the main public transport travel modes are public electric vehicle (regular bus), mass transit and taxi.

\subsection{Indicators Represent Urban Traffic Development}

The factors above have described the correlation of them between the urban traffic development situation from the perspective of supply, demand and the social economy. However, if the above factor data are used to analyze merely in the actual calculation, then it would be difficult to describe its relationship with the urban traffic development level. In the meanwhile the average traffic speed of the road network is selected as the token indicator of urban traffic development level [17]. While, the value of average traffic speed of the road network is influenced by many factors crossed. If we treat the factors as independent computation basis, it would cause inaccurate results and the demonstration would be lack of a scientific nature. For this reason, the main indicators affecting the average traffic speed of the road network should be researched. This paper uses the Eviews to carry out the correlation analysis to verify the relationship of the average traffic speed of road network and traffic congestion based on the original data of Beijing 2000-2010. That is to say, when the average traffic speed of the road network is selected as the token indicator, whether it is the optimum indicator representation for urban traffic congestion still needs to be verified. The main verifying method is to extract any of the factors mentioned above which has a relative high degree to the average traffic speed of the road network and the effect relationship is obvious. Finally, the Simple Pearson correlation coefficient method is performed to analyze. And the precise analysis results are shown in Tab.2.

Here, For the sake of writing, the following symbols are used to represent the name of each indicator:

SPEED: average traffic speed of road network $(\mathrm{km} / \mathrm{h})$

GDP: GDP (hundred million Yuan)

POP: Resident population (ten thousand people)

N-Car: Number of civilian vehicle (ten thousand vehicles)

M-Road: Road mileage (km)

A-Road: Road area (ten thousand $\mathrm{m}^{2}$ )

N-Bus: Number of public vehicle

P-Bus: number of public transport passenger

Here, the correlation test is taken by Eviews software. And the specific results obtained are shown in Tab.3.

The results demonstrate that the correlation coefficients of the average GDP, POP and other influencing factors between SPEED are all above 0.7. We can see that the correlation coefficient is higher, which means they are the main factors influencing the average traffic speed of the road network. And in the direction of the correlation, there presents a high negative correlation of SPEED between with POP, GDP and N-Car. As we know, the growth of each indicator's value will make a decrease of the value of SPEED. Besides, it puts forward a high positive correlation of SPEED between with the A-Road. As the value of the road area grows, the value of SPEED will also increase and the congestion can be weakened. Here, the research conclusions are the same as the above results of factor correlation analysis. Therefore, the SPEED is the measurement indicator of urban traffic congestion degree eventually in this paper. Additionally, depending on the econometric analysis principle of "from the general to the simple", the autocorrelation and colinearity of each indicator should be tested when the number of the indicator is large. At last, the selection of indicators is expected to be completed.

The results show that in Probit regression process, the robust test of P-Bus's coefficient is nonsignificant, and there is higher co-linearity between N-Bus and N-Car. After the removal of P-Bus, the values of $\mathrm{R}^{2}$ and AIC / SIC are experiencing noticeable change. Besides, co-linearity problems of M-Road 
Table 2. the indicator data related to traffic smooth in Beijing

\begin{tabular}{ccccccccc}
\hline Year & SPEED & GDP & POP & N-Car & M-Road & A-Road & N-Bus & P-Bus \\
\hline 2000 & 18.9 & 3161 & 1357 & 104.1 & 2471 & 3502 & 10353 & 34.8 \\
2001 & 19.0 & 3711 & 1383 & 114.5 & 2493 & 3701 & 12945 & 39.2 \\
2002 & 19.8 & 4330 & 1423 & 133.9 & 2504 & 3857 & 15046 & 43.5 \\
2003 & 20.1 & 5024 & 1456 & 163.1 & 3347 & 4315 & 16753 & 37.1 \\
2004 & 20.0 & 6033 & 1493 & 182.4 & 4064 & 7287 & 18451 & 43.9 \\
2005 & 23.4 & 6970 & 1538 & 209.7 & 4073 & 7437 & 18503 & 45.0 \\
2006 & 22.5 & 8118 & 1581 & 239.1 & 4419 & 7286 & 19522 & 39.8 \\
2007 & 20.5 & 9847 & 1633 & 273.4 & 4460 & 7632 & 19395 & 42.3 \\
2008 & 23.1 & 11115 & 1695 & 313.7 & 6186 & 8940 & 21507 & 47.1 \\
2009 & 23.1 & 12153 & 1755 & 368.1 & 6247 & 9179 & 21716 & 51.7 \\
2010 & 22.2 & 14114 & 1961 & 449.7 & 6355 & 9395 & 21548 & 50.5 \\
\hline
\end{tabular}

Data source: wind, Beijing traffic development annual report

and A-Road cannot be ignored, and it is unsuitable for them to be put into the same model. Thus, only M-Road is retained, because the correlation coefficient value of M-Road between SPEED is greater and has better stability. Therefore, the statistical magnitude of the 4 variances' Wald $\chi^{2}$ is 19.89 , the value of $p$ is 0.0005 , the likelihood of $\log$ pseudo is -2.2760393 , and Pseudo $\mathrm{R}^{2}$ is 0.5019 , with the fitting degree being acceptable [18]. Finally, indicators represented for urban traffic development are identified as: N-Car, POP, GDP, M-Road and N-Bus.

\section{The "Internet + traffic" and its Development Level}

\subsection{The Development Level of "Internet + traffic"}

Based on the above analysis the "Internet + traffic" is defined combined with "Internet +" definitions given by the government, and other various industries, integrated the related contents of transport. The definition of the "Internet + traffic" is such a process. First, make the traffic infrastructure, transportation, transportation characteristics Internet-enabled through using the Internet technology. Then all kinds of information about people, vehicles, roads, management and so on are integrated to provide transportation services. And last the service data resources are opened for the public to provide travel services for travelers. However, "Internet + traffic" is not a simple addition of two kinds of industry, but a process to make the both for full integration through some ways and means. Therefore, the paper described the integration development concept of "Internet + transportation" starting from the definition of "Internet + traffic". And the fusion model is defined as: when we research the integration of Internet and urban traffic, rather than on the specific mode of transportation. Namely from the macroscopic angle, the fusion of the "Internet +traffic" marked by the widespread application of Internet technology, led by the intelligent traffic, continuous innovated with personalized and diversified transport service mode, characterized by timely application. Then the new organization and service management system that the influence of "Internet +" on the traditional transportation process is put forward [19].

As a strong macroscopic indicator, it is very difficult to measure the development level of "Internet + traffic", because the pertinence and high correlation, and because the comprehensive and multi-angle indicators should be considered and pursued. Therefore, all the indicator factors must be comprehensively analyzed and the most appropriate target should be chosen.

The Highmoralmap has analyzed the development level of "Internet + traffic" in the research report "the 'Internet + traffic' urban index research report in China - 2016". The report selected 27 indicators in three areas and then the evaluation was carried out based on the 62 large and medium-sized cities. Finally, the development level of urban "Internet + traffic" was described by using the big data technology. The research report points out the top ten cities of the "Internet + traffic development: Beijing, Guangzhou, 
Table 3. the correlations between different indicators

\begin{tabular}{ccccccccc}
\hline $\begin{array}{c}\text { Correlation } \\
\text { Probability }\end{array}$ & SPEED & GDP & POP & N-Car & M-Road & A-Road & N-Bus & P-Bus \\
\hline \multirow{2}{*}{ SPEED } & 1.000 & 0.748 & 0.703 & 0.727 & 0.805 & 0.830 & 0.826 & 0.704 \\
& - & 0.008 & 0.016 & 0.011 & 0.003 & 0.002 & 0.002 & 0.016 \\
GDP & -0.748 & 1.000 & 0.982 & 0.992 & 0.967 & 0.929 & 0.893 & 0.828 \\
& 0.008 & - & 0.000 & 0.000 & 0.000 & 0.000 & 0.000 & 0.002 \\
POP & -0.703 & 0.982 & 1.000 & 0.995 & 0.934 & 0.888 & 0.851 & 0.822 \\
& 0.016 & 0.000 & - & 0.000 & 0.000 & 0.000 & 0.001 & 0.002 \\
N-Car & -0.727 & 0.992 & 0.995 & 1.000 & 0.955 & 0.905 & 0.867 & 0.832 \\
& 0.011 & 0.000 & 0.000 & - & 0.000 & 0.000 & 0.001 & 0.002 \\
M-Road & 0.85 & 0.967 & 0.934 & 0.955 & 1.000 & 0.956 & 0.916 & 0.827 \\
& 0.003 & 0.000 & 0.000 & 0.000 & - & 0.000 & 0.000 & 0.002 \\
A-Road & 0.830 & 0.929 & 0.888 & 0.905 & 0.956 & 1.000 & 0.937 & 0.824 \\
& 0.002 & 0.000 & 0.000 & 0.000 & 0.000 & - & 0.000 & 0.002 \\
N-Bus & 0.826 & 0.893 & 0.851 & 0.867 & 0.916 & 0.937 & 1.000 & 0.800 \\
& 0.002 & 0.000 & 0.001 & 0.001 & 0.000 & 0.000 & - & 0.003 \\
P-Bus & 0.704 & 0.828 & 0.822 & 0.832 & 0.827 & 0.824 & 0.800 & 1.000 \\
& 0.016 & 0.002 & 0.002 & 0.002 & 0.002 & 0.002 & 0.003 & - \\
\hline
\end{tabular}

Shenzhen, Wuhan, Shanghai, Tianjin, Ningbo, Chengdu, Chongqing and Xi 'an. Among them, Beijing occupies the first place with the index value of 87.91, and Guangzhou follows Beijing with the index value of 80.32. The two cities occupied the strategic high ground of "Internet + Transportation" development in China. In addition, through analyzing the comprehensive ranking of the 62 cities we find that the "Internet + traffic" development level in first-tier cities and coastal cities is higher than other inland cities. Among them, 8 cities out of the top 30 are from Guangdong province in the top 30 cities. That is to say, the overall development strength of "Internet + traffic" in Guangzhou is stronger. Not only that, the "Internet + traffic" in the central and western regions also had great progress under the guidance of the Belt and Road policy. Especially in Xi- 'an, Chengdu and Chongqing, the "Internet + traffic" has a strong development potential and entered the top ten in the country. These can make the "Internet + traffic" have a rapid rise in other western cities effectively. The above survey of "Internet + traffic" provided by Highmoralmap has reflected the universality, comprehensive and scientific rationality of sample enough. Also, through analyzing the "Internet + traffic" of top 10 cities we find that the intelligent transportation (e.g., Guangzhou, Wuhan), wisdom travel (e.g., Beijing, Shenzhen) and government influence (e.g., Beijing, Shanghai) in these cities are also among the top ten. Therefore, refer to the above conclusions, intelligent transportation, wisdom travel and government influences are seen as the measure indicators of "Internet + traffic" development level eventually, as showed in Fig.1.

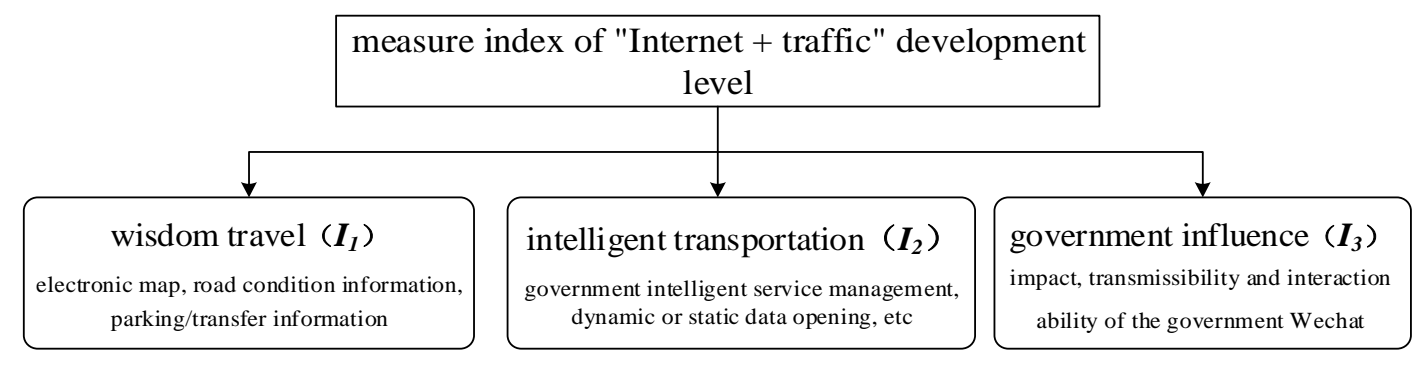

Figure 1. The measure index system of "Internet + traffic" development level 


\section{(1) Wisdom travel}

The main purpose of wisdom travel to provide special security technology for bus by using "Internet +" technology and Internet of Things technology, which can improve the service level of the bus. Meanwhile, to monitor passenger flow and abnormal events in the bus transfer station, subway transfer station, highway transfer station and railway transfer station. All of these will be good for optimizing the transfer scheduling, providing $\mathrm{P}+\mathrm{R}$ interchange service and enriching the distribution channels of various transportation information. Eventually, the wisdom travel can make better public transit and transfer services for the travelers. In addition, the "Internet + " technology is used to carry out technical reform and deepen the application of urban traffic. Then using "Internet + " technology to realize a comprehensive perception of the transport elements in the city administrative region. And then the advanced network communication technology and intelligent processing technology are employed to make active management from friendly urban transportation environment. Finally, totally over twenty kinds of information were published through using the wisdom travel system, such as the traffic service information of real-time traffic status, parking space reservation, taxi booking, public transportation transferring and bus arriving, etc. All of these are implemented through the Internet, mobile phone termination, vehicle positioning navigation terminal, mobile TV terminals, road traffic-induced screen and traffic radio totally more than 10 kinds of traffic information service mode [20].

\section{(2) Intelligent transportation}

As a giant complex system, intelligent transportation is constituted by the knowledge system, intelligence system, method system, skill system and ideology system. Also, definition content it covered is very extensive. This paper defines intelligence traffic as a system like the follows. To integrate the communication technology, information technology, electronics technology, vehicles technology and other advanced technology integration to apply in traffic areas. Then to obtain the solutions quickly and correctly, which can improve traffic conditions and make the maximum efficiency of the urban traffic. Here, we find that the deep fusion of "Internet +" in the transport system is an important technology and idea for constructing the intelligent transportation. Firstly, the valuable information is extracted from the massive traffic data quickly and accurately to make a quick calculation and scientific analysis based on the protection of advanced internet technology. Thus, the formidability, initiative, timeliness and cooperatively of traffic management can be improved widely. Secondly, a set of information sharing and exchange mechanism are established by integrating transportation information resources of all departments to make the collection, management and application of the comprehensive traffic data come true. Then the corresponding intelligent transportation comprehensive management systems would be constructed, such as the traffic control and intelligence system, illegal capture automatic recording system in running the red light, one-piece high definition card monitoring system, adaptive traffic signal control system, etc [21]. The combinative application of the "Internet + " with intelligent transportation system is shown in Fig.2.

Fig. 2 shows that the bottom layer are support systems, the middle layer is application systems and the top layer are mainly for the users. Systems in the bottom layer are all kinds of special intelligent subsystems for the road network traffic. They are direct participants and mainly act on the command, management and monitoring in traffic circulation. Also, they bring the basic guarantee for the running of application systems. For the middle layer application systems the main function is coordinating the communication of different departments involved in the transportation management by using "Internet +" technology. And then, the corresponding subsystems are formed, such as the traffic management information subsystem, data exchange subsystem, information processing subsystem and decision-making support subsystem, etc. Among them, the information of traffic violations, car frame management, traffic accidents, traffic commuting are processed comprehensively. Then the processing results are transmitted to the corresponding data center. Besides, the original road network traffic information collected by support systems is processed by the data exchange subsystem, and the results are transmitted to the data center. After that, two available information release channels are adopted to release the traffic information that has been processed by the subsystem in data centers. In one channel, the traffic information can be obtained initiatively based on the user's travel demand. This information has sharp features such as personalization and specificity. In another channel, the traffic information is released by the system. They are public information, such as traffic information, weather information, etc. Finally, the traffic information offered by the data center can not only provide travel service for travelers but also offer management decision-making references for traffic administrator 


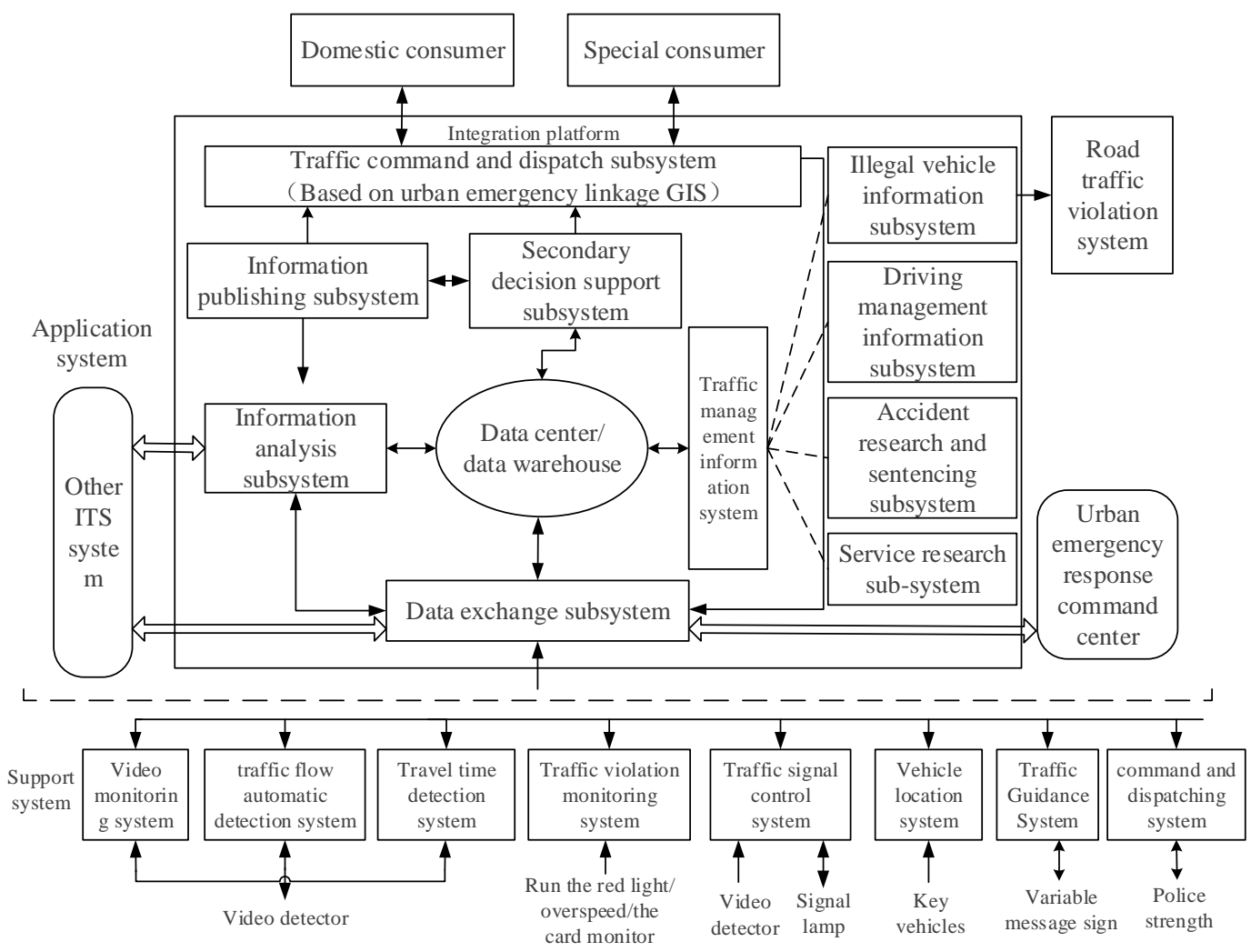

Figure 2. Combinative application of the "Internet +" with intelligent transportation systems

\section{(3) Government influence}

Government influence refers to the use of "Internet + " technology to promote big data sharing integration of all kinds of transportation system. The use of big data in traffic management can provide better service management through the integration of transportation industry data to promote resource sharing. These data are multitudinous, such as the data of the automakers and system operators, and the data of the key construction in the city like traffic information system, vehicle control system, data from electronic toll collection system, etc. Meanwhile, the diversified data deliver ways should be encouraged by the traffic management department. Also the equipment is encouraged to use. Such as the phone APP, vehicle navigation, road signal and road information board etc. Then the urban office traffic APP should be released and broadcasted. In addition, the professional team should be set up in charge of the software upgrading and maintenance, which can make mastery of the real-time traffic information easier.

\subsection{Measure of the "Internet + traffic" Development Level}

In this paper, the measuring method of the "Internet + traffic" development level is given by formula (1) based on the above analysis and the methods provided in "the 'Internet + traffic' urban index research report in China - 2016" by Highmoralmap.

$$
I_{1}=\sum_{j_{I_{1}}=1}^{m_{I_{1}}} w_{j_{I_{1}}} \cdot \frac{d_{j_{I_{1}} 0}}{\sum_{k_{I_{1}}=1}^{n} d_{j_{I_{1}} k_{I_{1}}}}
$$

In formula (1), $I_{1}$ is the indicator of wisdom travel. $w_{j_{1}}$ means the weight of jth secondary indicator, and expert marking is the main calculation method. $m_{I_{1}}$ is the number of the secondary indicator in wisdom travel. $d_{j_{I_{1}} 0}$ means the value of the jth secondary indicator. $d_{j_{I_{1}} k_{I_{1}}}$ means the value of the jth secondary indicator in the kth city. $n$ means the number of the city. 
The calculation method of $I_{2}$ and $I_{3}$ is identical to the method of $I_{1}$. We won't repeat it here. So after the standardized processing of each indicator the corresponding index will be obtained. Here, we still take $I_{1}$ as an example. Its index computation formula is as formula (2).

$$
I_{1}^{*}=\frac{I_{1}-I_{1 \min }}{I_{1 \max }-I_{1 \min }} \times 100 \%
$$

Then the total development level index of "Internet + traffic" can be measured based on formula (2), as showed in formula (3).

$$
\begin{aligned}
E_{\text {total }} & =W_{1} * I_{1}^{*}+W_{2} * I_{2}^{*}+W_{3} * I_{3}^{*} \\
& =\frac{\sum_{t=1}^{z} \alpha_{t}}{\sum_{t=1}^{z}\left(\alpha_{t}+\beta_{t}+\gamma_{t}\right)} * I_{1}^{*}+\frac{\sum_{t=1}^{z} \beta_{t}}{\sum_{t=1}^{z}\left(\alpha_{t}+\beta_{t}+\gamma_{t}\right)} * I_{2}^{*}+\frac{\sum_{t=1}^{z} \gamma_{t}}{\sum_{t=1}^{z}\left(\alpha_{t}+\beta_{t}+\gamma_{t}\right)} * I_{3}^{*}
\end{aligned}
$$

Among them, the weights of wisdom travel, intelligent transportation and government influence are $35.7 \%$, $38.8 \%, 25.5 \%$. All the weights are obtained by the expert marking method according to the importance level of each indicator (all the values are from 1 to 10, the higher the score the greater the importance). Then we get the weights by standardized processing. $\alpha_{t}, \beta_{t}, \gamma_{t}$ are the scores of each secondary indicator in corresponding primary indicator. $z$ means the number of experts who participate in the ratings.

\section{The Demand of Urban Traffic for "Internet + traffic"}

\subsection{Acquisitions of the Indicator Data}

First of all, "Internet + traffic" development indexes are calculated for the top 100 cities on the "Internet + traffic" development level. Then the sample cities are selected. They are the 30 provincial capital cities (municipalities directly under the central government, or autonomous region) (excluding Hong Kong, Macao and Taiwan, and because of the outlier characteristics of the data in Tibet, we exclude the data of Lhasa). Besides, we also choose six relatively developed cities: Dalian, Qingdao, Shenzhen, Ningbo, Xiamen and Suzhou. Finally, 36 central cities above are intended to be the sample cities. In addition, due to the characteristics of data, the establishment of "Internet + traffic" development planning needs to refer to the development status of urban traffic. While, because of the certain lag of statistical data, the calculation of the index should refer to the statistics of previous years. Therefore, considering the novelty of the indicator data, the "Internet + traffic" development index data of 2016 is taken as the calculation standard. Other indicator data are based on the year of 2015. The data of the corresponding indicator are shown in Tab.4.

\subsection{Method Selecting and Model Building}

\section{(1) Method selection}

The main purpose of constructing the "Internet + traffic" is to guide the road network travel reasonability. And the disordered traffic travel could be changed to orderly traffic running state maximally, which can effectively alleviate the urban traffic problems and improve the road network. However, if the demand relationship between the urban transportation development level and "Internet + transportation" is just argued by simple qualitative methods, it is difficult to clear the relationship of them. At this point, through the analysis of the paper's research purpose we find that the primary mission is to discuss the current demand conditions between the urban traffic development and the "Internet + traffic". Therefore, we set the urban traffic development level indicators as the explanatory variable, and the "Internet + traffic" index as the explained variable. That is, an explained variable is affected by numerous explanatory variables commonly So, after the comprehensive comparison of various econometric model methods, the multiple regression analysis is chosen finally. Here, the multiple regression model contains the following advantages. Firstly, when there are numerous indicators and data acquisition is difficult, the multiple 
Table 4. The indicator data of 36 cities

\begin{tabular}{|c|c|c|c|c|c|c|}
\hline City & GDP & N-Car & POP & M-Road & N-Bus & Internet+ Traffic \\
\hline Shijiazhuang & 3401.02 & 90.17 & 1002.81 & 1475 & 90657 & 15.41 \\
\hline Taiyuan & 1778.05 & 60.50 & 354.02 & 1780 & 39353 & 25.41 \\
\hline Hohhot & 1865.71 & 32.16 & 278.76 & 720 & 10189 & 10.6 \\
\hline Shenyang & 5017.54 & 98.43 & 804.65 & 2895 & 10275 & 21.64 \\
\hline Dalian & 5158.16 & 94.49 & 663.82 & 2899 & 7145 & 20.62 \\
\hline Changchun & 3329.03 & 66.48 & 757.7 & 3659 & 23935 & 34.13 \\
\hline Harbin & 3664.85 & 65.24 & 991.81 & 1427 & 21618 & 16.23 \\
\hline Nanjing & 5130.65 & 83.05 & 786.03 & 5599 & 19539 & 44.14 \\
\hline Hangzhou & 5949.17 & 124.81 & 851.97 & 2194 & 70304 & 43.71 \\
\hline Ningbo & 5163.00 & 87.74 & 744.29 & 1439 & 16689 & 52.07 \\
\hline Hefei & 2961.67 & 38.61 & 540.49 & 2013 & 16707 & 19.56 \\
\hline Fuzhou & 3123.41 & 43.37 & 699.27 & 1101 & 11108 & 18.63 \\
\hline Xiamen & 2060.07 & 38.54 & 353.13 & 1213 & 7987 & 39.61 \\
\hline Nanchang & 2200.11 & 36.24 & 502.66 & 965 & 6303 & 30.52 \\
\hline Jinan & 3910.53 & 79.74 & 674.62 & 4498 & 12297 & 45.47 \\
\hline Tsingtao & 5666.19 & 97.56 & 860.77 & 3409 & 15544 & 42.86 \\
\hline Zhengzhou & 4040.89 & 96.30 & 809.04 & 1338 & 21572 & 36.86 \\
\hline Wuhan & 5565.93 & 104.65 & 944 & 2682 & 9838 & 68.23 \\
\hline Changsha & 4547.06 & 100.87 & 684.35 & 1781 & 28502 & 36.22 \\
\hline Guangzhou & 10748.28 & 159.89 & 1228.96 & 6986 & 7396 & 80.32 \\
\hline Shenzhen & 9581.51 & 166.97 & 1016.1 & 12613 & 3099 & 71.78 \\
\hline Nanning & 1800.26 & 43.22 & 702.62 & 1307 & 21681 & 19.03 \\
\hline Haikou & 617.19 & 23.80 & 159.35 & 111 & 18808 & 8 \\
\hline Chengdu & 5551.33 & 259.93 & 1144.37 & 2610 & 5819 & 49.78 \\
\hline Guiyang & 1121.82 & 60.44 & 430.52 & 872 & 11416 & 24.78 \\
\hline Kunming & 2120.37 & 132.42 & 632 & 1420 & 2067 & 40.96 \\
\hline Xi'an & 3241.69 & 95.72 & 845.45 & 2428 & 18986 & 46.43 \\
\hline Lanzhou & 1100.39 & 24.61 & 323.56 & 906 & 9146 & 32.01 \\
\hline Xining & 628.28 & 30.99 & 221.01 & 433 & 7448 & 13.08 \\
\hline Yinchuan & 769.42 & 22.56 & 185.31 & 506 & 6202 & 8 \\
\hline Beijing & 14113.58 & 449.72 & 1910.96 & 6355 & 11584 & 87.91 \\
\hline Urumchi & 1338.52 & 127.14 & 311 & 1632 & 15085 & 23.51 \\
\hline Chongqing & 7925.58 & 114.30 & 2872 & 5130 & 14303 & 48.11 \\
\hline Tianjin & 9224.46 & 158.24 & 1263.73 & 5439 & 7297 & 54.94 \\
\hline Shanghai & 17165.98 & 175.51 & 2256.48 & 4713 & 27114 & 59.84 \\
\hline Suzhou & 9228.91 & 126.10 & 991.9 & 2904 & 7937 & 44.25 \\
\hline
\end{tabular}

Data source: China Statistical Yearbook, the city passenger statistics report of the Ministry of Transport, "Internet + traffic" city index research report in China - 2016.

regression model can avoid the interference arised from partial data deficiency. Moreover the fitting degree and the correlation between each factor can be expressed clearly by the multiple regression model. Secondly, the influence degree and influence law of the explanatory variables to the explained variables can be reflected by the multiple regression model. And also the regression equation would be fitted for the delayed prediction. Thirdly, the calculation results given by the multiple regression model are global optimum and could avoid the influence of local optimum. Besides, the contingency of the forecasting results 
can be peeled out and that makes the forecast more accurate. Finally, the accuracy of the calculation results is ensured. Here, we give the correlation results based on the data in Tab.4, as showed in Tab.5.

Table 5. The correlation of each indicator with "Internet + traffic"

\begin{tabular}{ccccccc}
\hline $\begin{array}{c}\text { Pearson Correlation } \\
\text { Sig(Two-tailed) }\end{array}$ & GDP & N-Car & POP & M-Road & N-Bus & Internet +traffic \\
\hline \multirow{2}{*}{ GDP } & 1.000 & 0.736 & 0.807 & 0.708 & -0.021 & 0.778 \\
& & 0.00 & 0.00 & 0.00 & 0.905 & 0.000 \\
N-Car & 0.736 & 1.000 & 0.610 & 0.549 & -0.051 & 0.736 \\
& 0.00 & & 0.00 & 0.001 & 0.770 & 0.000 \\
POP & 0.807 & 0.610 & 1.000 & 0.548 & 0.071 & 0.711 \\
& 0.00 & 0.00 & & 0.001 & 0.681 & 0.000 \\
M-Road & 0.708 & 0.549 & 0.548 & 1.000 & -0.159 & 0.735 \\
& 0.00 & 0.001 & 0.001 & & 0.355 & 0.000 \\
N-Bus & -0.021 & -0.051 & 0.071 & -0.159 & 1.000 & -0.172 \\
& 0.905 & 0.770 & 0.681 & 0.355 & & 0.315 \\
Internet+ traffic & 0.778 & 0.736 & 0.711 & 0.735 & -0.172 & 1.000 \\
& 0.00 & 0.00 & 0.00 & 0.00 & 0.315 & \\
\hline
\end{tabular}

The correlation analysis results in Tab.5 show that the correlation valueS of other indicators with "Internet + traffic" are more than 0.7 except for the N - Bus indicator. The high related degree means that the regression model could be built by the indicators. Therefore, the indicator of "N - Bus" is removed.

(2) Construction of the regression model

According to index screening result, the regression model of this paper is built as formula (4) showed based on the general multiple regression model

$$
Y=\beta_{0}+\beta_{1} X_{1}+\beta_{2} X_{2}+\beta_{3} X_{3}+\beta_{4} X_{4}+\varepsilon
$$

Among them, $k$ means the number of explanatory variable, $k=4$. $\beta_{j}(j=1,2,3,4)$ means the regression coefficient. $Y$ means the "Internet+ traffic" index (\%). $X_{1}$ means GDP. $X_{2}$ means N-Car. $X_{3}$ means POP. $X_{4}$ means M-Road $\varepsilon$ means the random error. We assume that $\varepsilon$ obeys the normal distribution.

Finally, the regression analysis results are achieved in Tab.6 and Tab.7 by using SPSS software.

Table 6. Model summary

\begin{tabular}{|c|c|c|c|c|c|c|c|c|}
\hline \multirow{2}{*}{ Model } & \multirow{2}{*}{$\mathrm{R}$} & \multirow{2}{*}{$\mathrm{R}^{2}$} & \multirow{2}{*}{$\begin{array}{c}\text { Adjusted } \\
\mathrm{R}^{2}\end{array}$} & \multirow{2}{*}{$\begin{array}{l}\text { Std. Error } \\
\text { of Estimate }\end{array}$} & \multicolumn{3}{|c|}{ Change Statistics } & \multirow{2}{*}{$\begin{array}{l}\text { Durbin- } \\
\text { Watson }\end{array}$} \\
\hline & & & & & $\begin{array}{c}\mathrm{R}^{2} \\
\text { Modify }\end{array}$ & $\begin{array}{c}\mathrm{F} \\
\text { Modify }\end{array}$ & $\begin{array}{l}\text { Sig. F } \\
\text { Modify }\end{array}$ & \\
\hline 1 & 0.778 & 0.605 & 0.593 & 12.85884 & 0.605 & 52.093 & 0.000 & - \\
\hline 2 & 0.821 & 0.673 & 0.653 & 11.87196 & 0.068 & 6.888 & 0.013 & - \\
\hline 3 & 0.851 & 0.725 & 0.699 & 11.06693 & 0.051 & 5.976 & 0.020 & 1.330 \\
\hline
\end{tabular}

The results in Tab.6 show that multiple correlation coefficient $\mathrm{R}=0.851$. Determination coefficient $\mathrm{R}^{2}$ $=0.725$, adjusted coefficient $\mathrm{R}^{2}=0.699$, and $\mathrm{Sig}=0.02<0.05$. So the fitting degree of the model is good. Besides, the Durbin-Watson=1.330 (DW=1.330). When comparing to the Durbin-Watson Test check list, we found that $1.18 \leq D W \leq 1.80$ if the sample capacity is 5 and the explanatory variable is equal to 5 . That means the variables are independent between each other. Additionally, the statistic observed value of the model $\mathrm{F}$ is 28.077 , and the value of $\mathrm{p}$ is 0.00 , which means there are linear relations of GDP, POP, 
Table 7. Coefficient table

\begin{tabular}{|c|c|c|c|c|c|c|c|}
\hline \multicolumn{2}{|c|}{ Model } & \multicolumn{2}{|c|}{ Unstandardized Coefficients } & \multirow{2}{*}{$\mathrm{t}$} & \multirow{2}{*}{ Sig. } & \multicolumn{2}{|c|}{ Co linearity Statistics } \\
\hline & & B & Std. Error & & & Tolerance & VIF \\
\hline \multirow{2}{*}{1} & $\mathrm{C}$ & 17.466 & 3.460 & 5.048 & 0.000 & \multirow{3}{*}{1.000} & \multirow{3}{*}{1.000} \\
\hline & $X_{1}$ & 0.0041 & 0.000 & 7.218 & 0.000 & & \\
\hline \multirow{3}{*}{2} & $\mathrm{C}$ & 15.637 & 3.270 & 4.782 & 0.000 & & \\
\hline & $X_{1}$ & 0.0027 & 0.000 & 3.666 & 0.001 & \multirow{3}{*}{$\begin{array}{l}0.499 \\
0.499\end{array}$} & \multirow{3}{*}{$\begin{array}{l}2.003 \\
2.003\end{array}$} \\
\hline & $X_{4}$ & 0.003 & 0.001 & 2.624 & 0.013 & & \\
\hline \multirow{4}{*}{3} & $\mathrm{C}$ & 13.390 & 3.184 & 4.206 & 0.000 & & \\
\hline & $X_{1}$ & 0.0015 & 0.000 & 1.744 & 0.091 & 0.327 & 3.062 \\
\hline & $X_{4}$ & 0.003 & 0.001 & 2.664 & 0.012 & 0.497 & 2.011 \\
\hline & $X_{2}$ & 0.085 & 0.000 & 2.444 & 0.020 & 0.457 & 2.189 \\
\hline
\end{tabular}

N-Car, M-Road and N-Bus between with "Internet + traffic" in the case of significance level of 0.05. Finally, the corresponding coefficients are obtained as showed in Tab.7.

In Tab.7, $\mathrm{C}=13.39$, shows that the model conforms to the real economic significance. Partial regression coefficient is $\beta_{1}=0.0015, \beta_{4}=0.003$ and $\beta_{2}=0.085$, and the corresponding probability is $0.091,0.012$ and 0.020. These mean that the significance test is approved. In addition, values of VIF are less than 5 and the tolerance values are more than 0.1, which means the collinear test is approved. Additionally, through the analysis of the standardized P - P figure we found that almost all the points are located on a 45 degrees line. So the random error term is basically consistent with the logarithmic normal distribution and the econometric significance test is approved. Eventually, the multiple linear regression equation is constructed as showed in formula (5).

$$
Y=13.39+0.0015 * X_{1}+0.085 * X_{2}+0.003 * X_{4}
$$

\subsection{Empirical Study}

Guangzhou is selected as the case city referred to the city ranking based on the "Internet + traffic" index. Firstly, indicator data of Guangzhou in 2016 are obtained from the "Guangzhou statistics information network". The GDP is 19610 (hundred million Yuan), N-Car is 223.78 (ten thousand vehicles) and M-Road is $7462.26 \mathrm{~km}$. Secondly, the "Internet + traffic" index of Guangzhou in 2017 is calculated by using formula (5). The result is presented in formula (6).

$$
Y_{2017}=13.39+0.0015 * 19610+0.085 * 223.78+0.003 * 7462.26=84.21
$$

Based on the real demand of urban traffic development in Guangzhou in 2017, the "Internet + traffic" development index is 84.21. The conclusion reflects the development of "Internet + traffic" plays an important role in solving the problem of urban transportation to a certain extent. Simultaneously, the multiple regression equation shows that GDP, N-Car and M-Road play a relatively dominant role in "Internet + transportation". First of all, there is a positive correlation relationship between the city GDP and "Internet + traffic" index, which is, the stronger the city GDP, the higher the "Internet + traffic" index. Secondly, as an important transportation mode of urban development, there also exists a positive correlation between N-Car and the "Internet + traffic". That is N-Car not only affects the urban "Internet + traffic" development demands, but also depends on "Internet + traffic development level to a certain extent. To carry out a simple sort of Tab.4 based on the indicators of N-Car and "Internet +traffic" index. We concluded that in the top 10 cities of N-Car there are 8 cities whose "Internet + traffic" indexes are within the scope of the top 10. Finally, the multiple regression equation (5) shows that the relative partial regression coefficient of the M-Road is higher than the GDP and the N-Car, which means the influence degree of "Internet + traffic" index is higher. Similarly, to carry out a simple sort of Tab.4 based on the 
indicators of M-Road and "Internet + traffic" index. We found that in the top 10 cities of M-Road there are also 8 cities whose "Internet + traffic" index within the scope of the top 10. Therefore, more attention should be paid to the influence of the above indicators when doing the "Internet + traffic" development planning.

The above analysis results tell us that the maximum efficiency can be obtained by employing the optimal costs only if the construction of "Internet + traffic" refers to the urban traffic development level. Among them, the intensity of GDP, N-Car and M-Road are stronger than the other indicators to the construction of "Internet + traffic". The importance sorting is $X_{2}>X_{4}>X_{1}$. Therefore, the reference sequence is from N-Car to M-Road, then to GDP when in building the "Internet + traffic". This can ensure the coincidence degree of the urban traffic actual demand with the "Internet + traffic" construction. Meanwhile, there are certain correlations between the above three factors. For example, the GDP and the N-Car are relatively higher if the M-Road is larger and the urban road network structure is more complex, which has demonstrated the above view fully.

\section{Conclusion}

The fusion of traditional traffic with the "Internet + " technology is gradually becoming an important way to solve urban traffic problems and construct the wisdom city. Now each city has also committed to strengthening the depth and breadth of the region's "Internet + traffic" construction. However, the research conclusion shows that it is not the more of construction of the "Internet + traffic" in a city, the better of the situation. The construction should be combined with the actual demand and the return on investment, only in this way can the optimal construction schemes be put forward. Therefore, different from the traditional research perspectives this paper started from the current situation of the urban traffic development. And based on which the construction demand of "Internet + traffic" is known as the breakthrough point in a city. First of all, the influencing factors of the urban traffic development were discussed detailedly and the indicators were extracted. Secondly, the definition and main contents of "Internet + traffic" were summarized. Then the evaluation indicators and evaluation model of the "Internet + traffic" development level were built. At last, multiple regression estimate model about the demand of urban traffic development level for the construction of "Internet + traffic" is given. And then the Guangzhou city was taken as an example to predict the "Internet + traffic" index value of Guangzhou in 2017. In conclusion, the paper has described the relationship between the "Internet + traffic" and the urban traffic development level. Its research conclusions have evident reference values and significances to the cities who have different types, different economic level and road network structure in "Internet + traffic" constructing. And also the construction of the "Internet + traffic" could be more scientific and reasonable based on the research results.

\section{Conflicts of Interest}

The author declares that there are not any conflicts of interest to declare regarding this work.

\section{Acknowledgments}

This work is supported by the Research on the cross-border integration develop drive mechanism and mode of "Internet + traditional industries" in Henan province sponsored by the Henan Province Office of Education (18A630047) and the Nanhu Scholars Program for Young Scholars of XYNU (2017).

Thanks for the suggestions given by Dr. Chen J. of Zhongnan University of Economics and Law.

\section{References}

1. Huang D.Q. 2015 The Meaning of the "Internet +" in the government work report of the National People's Congress and the Chinese Political Consultative Conference Computer and Network, 41(6), p.10-11. 
2. Li M. W., 2017. Research on the Mode and Suggestion of "Internet + Transportation" Fusion Development Journal of Xinyang Normal University ( Philos. \& Soc. Sci. Edit. ), 37(1), p.61-65.

3. Luo S. \& Hao J.H. \&Xiao Y.\& Nie X.Y., 2016. "Internet + Transportation": Exploration of Transportation Network Integration Travel. China Internet, (07), p.7-10.

4. Wang G.P., 2015. The Exploration of the Development Trend between the "Internet +" and the urban intelligent transportation. Technology \& Application, (15), p. 60-63.

5. Zhai J.T. \& Wang Z.P. \& Wang L.Y., 2015. The Reform and Development of Urban Transportation under the "Internet + Transportation" Era. Urban Transportation, (09), p.70-74.

6. Zhao G.H., 2016. The Evolution and Policy of "Internet +" Transport Service in China. Circulation economy in China, (3), p. 39-48.

7. Chen G.P., 2016. Research on the Private Cars Sharing Mode to Alleviate Urban Traffic Congestion in The "Internet + Transportation" Perspective. Urban Development Studies, 23(2), p.105-109.

8. Lu X.Y. \& Xu Z.H. \& Xu Z., etc., 2012. Urban Traffic Congestion Detection Based on Clustering Analysis of Real-time Traffic Data. Journal of Geo-Information Science, (6), p.775-780.

9. HU Q.Z. \& Liu Y.S. \& Guo T.Y., 2012. Space-Time Distribution Model on State Monitoring of Urban Traffic Congestion. Journal of Transportation Systems Engineering and Information Technology, (3), p.41-45 + 58.

10. Guan S.Q. \& Yun J. \& Li M.W., 2016. The Contribution Research of Wuhan ETC System to the Improvement of Smooth Traffic. Mathematics in Practice and Theory, (7), p.81-86.

11. Li M.W. \& Yun J. \& Liu N., 2015. Calculating the Contribution Rate of Intelligent Transportation System in Improving Urban Traffic Smooth Based on Advanced DID Model. Mathematical Problems in Engineering, Volume 2015 (2015), Article ID 564230, 12 pages.

12. Li M.W., 2017. Research on the Contribution of ITS in Improving Traffic Smooth Based on the C-D Production Function. Mathematics in Practice and Theory, (7), p.192-197.

13. Chen G., 2016. Research on the Private Cars Sharing Mode to Alleviate Urban Traffic Congestion in The "Internet + Transportation" Perspective. Urban Development Studies, 22(1), p.83-93.

14. Liu J.G. \& Ma D.Q. \& Chen C.D. \& Yu T.T., 2016. Research on Innovation Paths of Business Model under"Internet + "Formats Based on Ground Theory-A Case Study of Di Di Taxi. Soft Science, (7), p.30-34.

15. Oh S. \& Jang JW., 2017. A Scheme to Smooth Aggregated Traffic from Sensors with Periodic Reports. Sensors, $17(3)$, p.503.

16. Lindov O. \& Causevic S. \& Bukalo E., 2013. Modular Innovative Solutions for Smooth and Safe Traffic Flows in the Cities. Suvremeni Promet - Modern Traffic, 33.

17. Li M. \& Yu L. \& Zhai Z., et al., 2016. Development of Emission Factors for an Urban Road Network Based on Speed Distributions. Journal of Transportation Engineering, 142(9), p.101-109.

18. Girolami M. \& Rogers S., 2006. Variational Bayesian Multinomial Probit Regression with Gaussian Process Priors. Neural Computation, 18(8), p.1790-1817.

19. Dai D.B. \& Fan T.J. \& Liu X.T., 2016. The Interactive Performance between Internet Technology Development and Current Economic Development in China. China Soft Science, (8), p.184-192.

20. Zhang G W., 2016. Time-sharing Lease and Wisdom Travel. Journal of Transportation Systems Engineering \& Information Technology, 32(3), p.38-45.

21. Panciera R. \& Khan A. \& Rizvi SJR, et al., 2016. The influence of travel time on emergency obstetric care seeking behavior in the urban poor of Bangladesh: a GIS study. Bmc Pregnancy \& Childbirth, 16(1), p.240. 